\title{
POSTOCCLUSIVE REACTIVE HYPEREMIA IN HAND-ARM VIBRATION SYNDROME
}

\author{
ZLATKA STOYNEVA ${ }^{1,2}$ \\ ${ }^{1}$ Medical University of Sofia, Sofia, Bulgaria \\ University Hospital St. Ivan Rilsky, Clinic of Occupational Diseases \\ ${ }^{2}$ Medical University of Plovdiv, Plovdiv, Bulgaria \\ Department of Occupational Diseases
}

\begin{abstract}
Objectives: To assess laser Doppler-recorded postocclusive reactive hyperemic responses in vibration-induced Raynaud's phenomenon and compare it with primary and secondary to sclerodermy Raynaud's phenomenon. Material and Methods: Thirty patients with vibration-induced Raynaud's phenomenon and 30 healthy controls and patients with primary and secondary to sclerodermy Raynaud's phenomenon were investigated. Fingerpulp skin blood flow was monitored by laser Doppler flowmetry during postocclusive reactive hyperemia test. Results: Lower initial perfusion values were established in all the patients with Raynaud's phenomenon compared to the healthy controls $(\mathrm{p}<0.0001)$. The postocclusive reactive hyperemic peak was lower in all the Raynaud's phenomenon groups compared to the controls $(\mathrm{p}<0.0001)$. The postocclusive and basal perfusions were lower in the secondary Raynaud's phenomenon groups compared to the control and the primary Raynaud's phenomenon groups $(\mathrm{p}<0.0001)$. The velocities to postocclusive hyperemic peak were lower in all the Raynaud's phenomenon patients $(\mathrm{p}<0.0001)$, so were in the vibration-induced $(\mathrm{p}<0.002)$ and the sclerodermy Raynaud's phenomenon $(p<0.004)$ groups in relation to the primary Raynaud's phenomenon group. The perfusion values and the velocities were significantly influenced by the initial superficial skin temperatures and perfusions, while the velocities were dependent also on gender, and the hyperemic peak on age. Conclusions: Postocclusive reactive hyperemia is abnormal in all Raynaud's phenomenon patients. Laser Doppler-recorded reactive hyperemia test contributes to diagnosing Raynaud's phenomenon and has proved to be valuable for group analysis. The applied method is not sensitive enough to discriminate adequately the type of Raynaud's phenomenon among individual cases.
\end{abstract}

Key words:

Hand-arm vibration syndrome, Reactive hyperemia test, Laser Doppler flowmetry, Raynaud's phenomenon, Sclerodermy, Microcirculation

\section{INTRODUCTION}

Chronic exposure to hand-transmitted vibration at work causes microvascular disorders of the hands with paroxysms of Raynaud's phenomenon (RP) characterized by intermittent digital blanching of the fingers followed by cyanosis and/or erythema. Raynaud's phenomenon is the main clinical manifestation of hand-arm vibration syndrome (HAVS) and is usually accompanied by peripheral nervous and/or musculoskeletal symptoms in the hands and arms.

Contradictory attitudes about the mechanisms of the vibration-induced RP (vRP) exist since its first description at the beginning of the 20th century. Nowadays, multifactorial pathophysiological mechanisms are supposed

Supported by grant "Laser Doppler-recorded autonomic and microcirculatory dysfunctions in Raynaud's phenomenon” from Medical University of Sofia. Grant manager: Zlatka Stoyneva, M.D., Ph.D.

Received: August 6, 2015. Accepted: September 8, 2015.

Corresponding author: Z. Stoyneva, Medical University of Sofia, University Hospital St. Ivan Rilsky, Clinic of Occupational Diseases, 15 Acad. Ivan Geshov Bld., 1431 Sofia, Bulgaria (e-mail: zlatka_stoyneva@yahoo.com). 
with interrelations between functional and structural abnormalities of the blood vessel wall and the endothelium, disorders of the neural control of the vascular tone and the impairment of blood flow and/or endothelial injury $[1,2]$.

Skin blood flow is regulated by neural and local control mechanisms. Sympathetic vasoconstrictor fibers have tonic vasoconstrictor influence on skin vessels, especially in the volar parts of the hands and fingers with abundant arterio-venular anastomoses. The local control mechanisms, independent of nerve and hormone control, include vasodilators, such as decreased oxygen partial pressure, hydrogen ion, locally released metabolites, such as adenosin, and increased concentrations of potassium with more pronounced effect in short-term hypoxia. More important as a local regulator of vascular tone are the vascular enodothelium producing vasodilators, such as nitric oxide (NO), prostacyclin and endothelium-derived hyperpolarizing factors and vasoconstrictors, such as endothelin, platelet activating factors [3,4]. Endothelial damage and dysregulation of vascular tone contribute to vibration-induced RP $[5,6]$.

Postocclusion reactive hyperemia is the sudden increase in blood flow after release of a transient occlusion of the proximal artery and is used as integrated test to study microvascular function [7]. Its mechanisms are not well known. It is supposed to be mediated by a local reflex including sensory nerves, a myogenic response and some metabolic and endothelial vasodilators, probably endothelial-derived hyperpolarizing factors, such as large-conductance calcium activated potassium channels (BKCa) $[8,9]$ since reactive hyperemic response is not dependent on nitric oxide pathway [10,11] or on cyclooxygenase-derived prostanoids [8].

Laser Doppler flowmetry (LDF) is the gold standard to evaluate skin microcirculation and its reactivity to various stimuli [12]. Laser Doppler-recorded postocclusive reactive hyperemia test in vRP patients has not been reported.

\section{Objective}

The study aimed to assess laser Doppler-recorded postocclusive reactive hyperemic (PORH) responses in vibration-induced RP and compare them with the primary and the secondary to sclerodermy RP.

\section{MATERIAL AND METHODS \\ Patients}

A hundred and twenty subjects were included in the study after informed consent: 1 st group - 30 healthy controls, 2nd group - 30 primary RP patients (pRP), 3rd group - 30 patients with systemic sclerosis-related secondary RP (sclRP), and 4th group - 30 vibration-induced secondary RP patients (vRP). Skin blood flow was measured by laser Doppler flowmetry (LDF) at a finger pulp with most frequently declared ischemic attacks. The fingerpulps have abundant arteriovenous anastomoses richly sympathetically innervated. Raynaud's phenomenon affects predominantly these specialized in thermoregulation areas of the skin [13]. The study was performed after ethics committee approval. Vibration-induced secondary RP was diagnosed in workers exposed to hand-arm vibration with manifestations of RP, musculoskeletal and/or peripheral nervous signs and symptoms in the upper limbs, negative serologic investigations, and no visceral pathology. Primary RP patients were diagnosed by a manifestation of RP, negative serologic investigations, normal capillaroscopy, no visceral pathology. Patients with RP secondary to systemic sclerosis fulfilled the following criteria: sclerosis of the skin, RP, sclerodermalike pattern of capillaroscopy, and positive autoantibodies. The patients and controls had no co-morbidities like diabetes mellitus, neuropathy, polyneuropathy. Non-steroid antiinflammatory drugs were administered in some of the patients, but no vasoactive drugs were used prior to the study.

\section{Measurement of skin blood flow}

The perfusion was measured in arbitrary perfusion units (PU) with a single-point laser Doppler system 
PeriFlux 4001 Master and PeriTemp4005 Heater with a single-point angled small thermostatic laser Doppler probe 457(357) for local heat provocation (PERIMED, Stockholm, Sweden). Periflux filters $32 \mathrm{kHz}$ and a time constant of $0.2 \mathrm{~s}$ were used in all the measurements. The probes were calibrated before starting the investigation using a suspension of latex particles (PF 100 Motility Standard), as recommended by the manufacturer. The probe holders were attached to the skin with a double adhesive tape.

\section{Study protocol}

The investigations were preceded by a 20 -min rest in a supine position for adaptation to the laboratory conditions with a temperature of the air $22 \pm 2^{\circ} \mathrm{C}$. Physical and mental stimulations were reduced to a minimum to avoid sympathetic activation, which might affect skin blood flow. The investigations were performed in the morning after light breakfast and at a normal arterial blood pressure for reducing the influence of metabolic and hemodynamic mechanisms on the hyperemic responses.

The resting fingerpulp skin perfusions and the superficial skin temperatures were monitored as initial values (initial fingerpulp skin perfusion (PUi), initial superficial temperature (Ti)) for $5 \mathrm{~min}$. Afterwards, the thermostatically controlled probe holder was maintained throughout the measurements at a temperature of $32^{\circ} \mathrm{C}$ in order to minimize the thermally induced variability of the acral cutaneous circulation [14] and the PORH response, dependent on the basal skin perfusion (PUb) [15]. The patients' PUb was registered for $5 \mathrm{~min}$. Then the digital arterial occlusion was done by inflation of a blood pressure cuff over the proximal phalanx of the finger for 3 min to suprasystolic pressure values to measure the biological zero (PUbz) (i.e., the perfusion during the ischemic occlusive block). Afterwards the cuff was deflated and the PORH perfusion and PORH peak (PUrh) was measured for $5 \mathrm{~min}$. The time to peak blood flow $(\mathrm{t})$ was registered automatically.

\section{Parameters analyzed}

The following parameters were analyzed: initial fingerpulp skin perfusion (PUi) and initial superficial temperature (Ti), basal perfusion (PUb) measured at $32^{\circ} \mathrm{C}$ skin temperature, biological zero (PUbz) and PORH peak (PUrh) defined as the highest blood flow value after release of the pressure cuff, time to peak ( $\mathrm{t}$ ). Microvascular vasodilator response indices, improving the reproducibility of the method [16] were calculated: delta reactive hyperemia $(\triangle \mathrm{RH})$ as PUrh-PUb; percent change of reactive hyperemia $(\% \mathrm{RH})$ as $(\Delta \mathrm{RH} / \mathrm{PUb}) \times 100$; the velocity of PORH microvascular response (Vrh) calculated through dividing of delta reactive hyperemia by the time to peak blood flow $(\Delta \mathrm{RH} / \mathrm{t})$.

\section{Statistical analysis}

The mean values \pm standard deviations were calculated. Comparisons of variables within groups across all phases of the protocol were done by Wilcoxon matched pairs signed rank test and between groups by Bonferroni's multiple comparison test for unpaired data using SPSS software package. Differences were considered significant when $\mathrm{p} \leq 0.05$. General linear model (univariate ANOVA) was performed to analyze perfusion values and indices between groups, controlled by age, gender and initial superficial skin temperature.

\section{RESULTS}

\section{Subjects}

The vRP study population consisted of 30 patients occupationally exposed to hand-arm vibration generated by hand-held vibrating tools: 22 miners working most of the time with hammer drills and 8 lumberjacks using regularly chainsaws, with $12.3 \pm 5.4$ years of service. According to the Stockholm Workshop scale criteria, 21 of the hands were classified at 2nd stage (the moderate grade with occasional attacks of the distal and middle phalanges of one or more fingers) and 9 were at 3rd stage (the severe 
Table 1. Study groups by age, gender, and initial fingerpulp skin temperature

\begin{tabular}{|c|c|c|c|c|}
\hline \multirow[t]{2}{*}{ Group } & \multicolumn{2}{|c|}{$\begin{array}{l}\text { Respondents } \\
{[\mathrm{n}]}\end{array}$} & \multirow{2}{*}{$\begin{array}{c}\text { Age } \\
\text { [years] } \\
(\mathrm{M} \pm \mathrm{SD})\end{array}$} & \multirow{2}{*}{$\begin{array}{c}\text { Initial skin temperature } \\
{\left[{ }^{\circ} \mathrm{C}\right]} \\
(\mathrm{M} \pm \mathrm{SD})\end{array}$} \\
\hline & males & females & & \\
\hline Controls & 16 & 14 & $44.1 \pm 9.3$ & $32.0 \pm 3.3$ \\
\hline $\mathrm{pRP}$ & 2 & 28 & $38.4 \pm 8.2$ & $24.5 \pm 4.9^{* * * *}$ \\
\hline sclRP & 14 & 16 & $51.3 \pm 13.1$ & $25.8 \pm 4.2^{* * * *}$ \\
\hline vRP & 30 & 0 & $48.2 \pm 8.2$ & $24.0 \pm 4.2^{* * * *}$ \\
\hline
\end{tabular}

pRP - primary Raynaud's phenomenon; sclRP - systemic sclerosis Raynaud's phenomenon; vRP - vibration-induced Raynaud's phenomenon.

$\mathrm{M}$ - mean; SD - standard deviation.

${ }^{*} \mathrm{p}<0.05 ;{ }^{* *} \mathrm{p}<0.01 ; * * \mathrm{p}<0.002 ;{ }^{* * * *} \mathrm{p}<0.0001$ (compared to the control group).

grade with frequent attacks affecting all phalanges of most fingers) [17].

There were no statistical differences in age between the RP groups and the healthy controls, but the pRP patients were younger than the $\mathrm{VRP}(\mathrm{p}<0.001)$ and the sclRP $(\mathrm{p}<0.0001)$ patients (Table 1$)$. The vRP group comprised only men and the pRP group included mainly females.

\section{Initial values}

The Ti of the RP patients were significantly lower compared to the controls $(\mathrm{p}<0.0001)$ (Table 2). So were the PUi values in both primary and secondary RP groups in relation to the group of healthy subjects $(\mathrm{p}<0.0001)$ (Table 3). The Ti and the PUi were not significantly different between the RP groups. A considerable overlap of the skin temperatures and the flux values in the individual cases between the groups was established, especially between the controls and the primary RP patients.

\section{Perfusions during the postocclusive reactive hyperemia test}

The PUb values were lowest in the scIRP, followed by the pRP and finally by the vRP patients; they did not differ significantly between the RP groups (Figure 1). The mean PUb in the vRP group was not statistically different from the other RP groups ( $p>0.05)$. The PUb in $\operatorname{sclRP}(\mathrm{p}<0.002)$ and $\mathrm{pRP}(\mathrm{p}<0.01)$ were significantly lower than in the controls. The PUbz values were not significantly different between the investigated groups. The average PUrh was significantly lower in all RP groups compared to controls $(\mathrm{p}<0.0001)$. The lowest PUrh was in the sclRP patients, which was lower compared to the pRP patients, too $(\mathrm{p}<0.001)$. The PUrh between

Table 2. Fingerpulp perfusions during postocclusive reactive hyperemia test in study groups

\begin{tabular}{|c|c|c|c|c|}
\hline \multirow[t]{2}{*}{ Group } & \multicolumn{4}{|c|}{$\begin{array}{c}\text { Perfusion } \\
\text { [PU] } \\
(\mathrm{M} \pm \mathrm{SD})\end{array}$} \\
\hline & initial & basal at $32^{\circ} \mathrm{C}$ & biological zero & postocclusive peak \\
\hline Controls & $141.1 \pm 44.2$ & $99.3 \pm 44.7$ & $2.77 \pm 0.7$ & $220.0 \pm 58.7$ \\
\hline $\mathrm{pRP}$ & $53.2 \pm 66.2^{* * * * *}$ & $54.8 \pm 55.9^{* *}$ & $2.50 \pm 0.9$ & $150.6 \pm 62.3^{* * * *}$ \\
\hline sclRP & $29.0 \pm 31.1^{* * * *}$ & $51.2 \pm 49.5^{* * *}$ & $2.42 \pm 0.7$ & $86.2 \pm 82.2^{* * * *}$ \\
\hline vRP & $46.6 \pm 42.2^{* * * *}$ & $81.0 \pm 52.5$ & $2.50 \pm 0.9$ & $125.3 \pm 44.5^{* * * *}$ \\
\hline
\end{tabular}

PU - perfusion unit. Other abbreviations as in Table 1.

${ }^{*} \mathrm{p}<0.05 ;{ }^{* *} \mathrm{p}<0.01 ; * * \mathrm{p}<0.002 ;{ }^{* * * *} \mathrm{p}<0.0001$ (compared to the control group). 
Table 3. The reactive hyperemia response indices

\begin{tabular}{|c|c|c|c|}
\hline \multirow{2}{*}{ Group } & \multicolumn{3}{|c|}{$\begin{array}{c}\text { Index } \\
(\mathrm{M} \pm \mathrm{SD}) \\
\end{array}$} \\
\hline & $\begin{array}{c}\Delta \mathrm{RH}(\mathrm{PUrh}-\mathrm{PUb}) \\
{[\mathrm{PU}]}\end{array}$ & $\begin{array}{c}\% \mathrm{RH}(\Delta \mathrm{RH} / \mathrm{PUb}) \\
{[\%]}\end{array}$ & $\begin{array}{c}\operatorname{Vrh}(\Delta \mathrm{RH} / \mathrm{s}) \\
{[\mathrm{PU} / \mathrm{s}]}\end{array}$ \\
\hline Controls & $120.7 \pm 43.0$ & $186.2 \pm 204.0$ & $9.0 \pm 3.6$ \\
\hline $\mathrm{pRP}$ & $95.8 \pm 46.7$ & $280.6 \pm 192.3$ & $5.7 \pm 3.8^{* * * *}$ \\
\hline sclRP & $35.0 \pm 56.8^{* * * *}$ & $307.5 \pm 783.0$ & $2.9 \pm 2.7^{* * * *}$ \\
\hline vRP & $44.4 \pm 33.1^{* * * *}$ & $128.8 \pm 179.1$ & $2.8 \pm 2.0^{* * * *}$ \\
\hline
\end{tabular}

$\triangle \mathrm{RH}$ - the difference between PUrh and PUb; PUrh - reactive hyperemia perfusion; PUb - basal perfusion at $32^{\circ} \mathrm{C}$ superficial skin temperature; $\% \mathrm{RH}$ - the percent change of postocclusive perfusion in relation to the basal perfusion; Vrh - velocity of postocclusive perfusion increase to the peak value. Other abbreviations as in Table 1 and 2.

${ }^{*} \mathrm{p}<0.05 ;{ }^{* *} \mathrm{p}<0.01 ;{ }^{* * *} \mathrm{p}<0.001 ;{ }^{* * *} \mathrm{p}<0.0001$ (Bonferroni's multiple comparison test for unpaired data in relation to the controls).

the vRP and the pRP and sclRP groups were not significantly different.

There were significant differences between PUb and PUrh within each investigated group.

\section{Reactive hyperemia vasodilator response indices}

The $\Delta \mathrm{RH}$ in the secondary vRP and sclRP groups were lower than in the control and pRP groups $(\mathrm{p}<0.0001)$. There were no significant differences in $\triangle \mathrm{RH}$ between the vRP and the sclRP groups and between pRP and the controls.

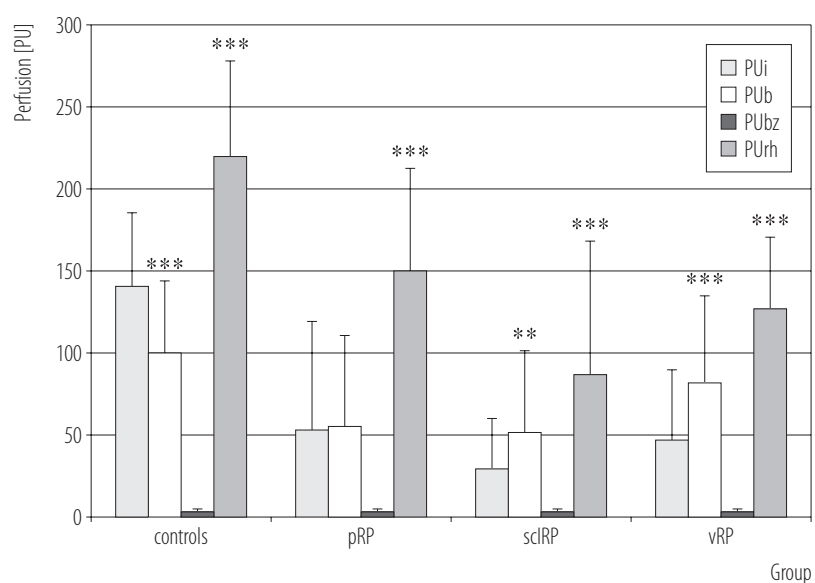

PUbz - biological zero. Other abbreviations as in Table 1 and 3.

$* \mathrm{p}<0.05 ;{ }^{* *} \mathrm{p}<0.001 ;{ }^{* * *} \mathrm{p}<0.0001$ (within group comparison by Wilcoxon matched pairs signed-rank test).

Fig. 1. Postocclusion reactive hyperemia response
The \% RH was not significantly different between the investigated groups, though in the vRP patients the values were the lowest.

The Vrhwas lower in all the RP groups $(\mathrm{p}<0.0001)$. The Vrh in the vRP $(\mathrm{p}<0.002)$ and sclRP $(\mathrm{p}<0.004)$ groups was lower than in the $\mathrm{pRP}$ group. The Vrh between vRP and sclRP were not significantly different.

\section{General Linear Model}

The F statistics by general linear model analysis showed significant differences in the PUi, PUb and PUrh perfusions, $\Delta \mathrm{RH}$ and $\mathrm{Vrh}$ indices across the groups (Table 4). The perfusion values and the Vrh were significantly associated with the Ti of the fingers. The PUi and PUb perfusions and the Vrh were dependent on gender as well. The PUrh were influenced also by the age. The $\Delta \mathrm{RH}$ index was the only parameter not influenced by age, initial temperature or gender.

\section{DISCUSSION}

The study investigated laser Doppler-recorded PORH responses in vRP patients, comparing them with pRP, sclRP and healthy subjects. The initial superficial skin temperatures and the perfusion values of the fingers in primary and secondary RP groups were significantly lower compared 
Table 4. F statistics data by general linear model (ANOVA)

\begin{tabular}{lrrrrrr}
\hline \multirow{2}{*}{\multicolumn{1}{c}{ Perfusions and indices }} & \multicolumn{7}{c}{$\begin{array}{c}\text { Statistics } \\
\text { [F }(\mathrm{p})]\end{array}$} \\
\cline { 2 - 7 } & \multicolumn{1}{c}{$\mathrm{PUi}$} & \multicolumn{1}{c}{ PUb } & \multicolumn{1}{c}{ PUrh } & \multicolumn{1}{c}{$\Delta \mathrm{RH}$} & $\% \mathrm{RH}$ & \multicolumn{1}{c}{ Vrh } \\
\hline Group & $16.43(0.0001)$ & $5.20(0.0020)$ & $11.60(0.0001)$ & $12.61(0.0001)$ & $1.83(0.1450)$ & $9.62(0.0001)$ \\
Initial superficial skin temperature & $60.17(0.0001)$ & $27.12(0.0001)$ & $10.08(0.0020)$ & $0.42(0.5200)$ & $2.27(0.1340)$ & $13.99(0.0001)$ \\
Age & $1.81(0.1810)$ & $2.20(0.1410)$ & $4.63(0.0340)$ & $1.98(0.1620)$ & $0.53(0.4740)$ & $1.87(0.1740)$ \\
Gender & $28.91(0.0001)$ & $15.61(0.0001)$ & $2.59(0.1100)$ & $2.27(0.1340)$ & $0.15(0.6960)$ & $7.72(0.0060)$ \\
\hline
\end{tabular}

PUi - initial perfusion. Other abbreviations as in Table 3.

to the control group. The data are consistent with those obtained by some authors $[18,19]$ but do not confirm others, who did not find differences in fingertip blood flow between control subjects and patients with RP [20]. The basal perfusion values at the thermoneutral $32^{\circ} \mathrm{C}$ skin temperature were significantly lower in sclRP and $\mathrm{pRP}$ groups but not in vRP group.

A considerable interindividual scattering of the initial resting fingerpulp perfusions with an overlap between the healthy controls and the primary RP patients and between the primary and the secondary RP patients was established, which makes the evaluation of the individual cases difficult and confirms the results of many investigators. The PORH peak was significantly lower in all RP patients, the lowest being in the sclRP patients. Though regular physical activity modifies the reactivity of vascular smooth muscle cells and enhances endothelium-dependent vasodilatation [21], the PORH responses in vRP, working with heavy loads and physical overstrain, were similar to $\mathrm{pRP}$ and sclRP. Our data are consistent with the results of other investigators concerning the reduced postocclusive hyperemic responses in sclRP [22-27] but not in pRP [28]. No data are accessible about the noninvasive laser Dopplerrecorded fingerpulp skin microvascular reactivity to temporary occlusion in vRP.

The major mediators of PORH are the sensory nerves through a local axon reflex $[7,8]$, the endothelium-derived hyperpolarizing factors (EDHFs) [27] and the recently described epoxyeicosatrienoic acids with vasodilator effect [28]. Therefore, some of these pathways or not well defined interactions between the different mechanisms were abnormal in RP patients but not necessarily in the same way in primary and secondary RP.

The study has some limitations regarding the number of investigated patients, their sex and age, which depend on the diseases' epidemiology. Other limitations are methodology-related, i.e., the semi-quantitative assessment of skin blood flow in arbitrary PU, the inter-individual, spatial and temporal flux variability. Though the singlepoint LDF is reproducible to assess PORH on the finger pad $[29,30]$, the analyzed parameters are not standardized [9,31]. Otherwise, the method of investigation is noninvasive, easy to apply, determines the dynamic perfusion changes independent of the underlying muscle blood flow [32]. Further investigations are needed.

\section{CONCLUSIONS}

The postocclusive reactive hyperemia is abnormal in vRP, sclRP and in pRP. Laser Doppler-recorded reactive hyperemia test contributes to the diagnosis of RP. The vasodilator indices, reflecting the postocclusion perfusion increase, differentiated best between primary and secondary types of RP. The applied method is not sensitive enough to discriminate adequately the type of RP among individual cases, but has proved valuable for group analysis. Laser Doppler flowmetry coupled with reactive 
hyperemia test is a valuable noninvasive tool for real-time assessment of the skin microcirculation and the integrative vasomotor reactivity.

\section{ACKNOWLEDGMENTS}

The author thanks the Clinic of Rheumatology for their patient participation, Ms. Boryana Boeva for her valuable statistical assistance and Mr. Ognyan Paskalev for his computer help.

\section{REFERENCES}

1. Stoyneva Z, Lyapina M, Tzvetkov D, Vodenicharov E. Current pathophysiological views on vibration-induced Raynaud's phenomenon. Cardiovasc Res. 2003;57(3):615-24, http://dx.doi.org/10.1016/S0008-6363(02)00728-9.

2. Wigley FM, Herrick AL, Flavahan NA, editors. Raynaud's phenomenon. A guide to pathogenesis and treatment. New York: Springer Verlag; 2015. p. 394, http://dx.doi. org/10.1007/978-1-4939-1526-2.

3. Cines DB, Pollak ES, Buck CA, Loscalzo J, Zimmerman GA, McEver RP, et al. Endothelial cells in physiology and in the pathology of vascular disorders. Blood. 1998;91(10):3527-61.

4. Feletou M, Vanhoutte PM. Endothelium-derived hyperpolarizing factor: Where are we now? Arterioscler Thromb Vasc Biol. 2006 Jun;26(6):1215-25, http://dx.doi.org/10.1161/01. ATV.0000217611.81085.c5.

5. Curry BD, Bain JL, Yan JG, Zhang LL, Yamaguchi M, Matloub HS, et al. Vibration injury damages arterial endothelial cells. Muscle Nerve. 2002;25(4):527-34, http://dx.doi. org/10.1002/mus.10058.

6. White CR, Haidekker MA, Stevens HY, Frangos JA. Extracellular signal-regulated kinase activation and endothelin-1 production in human endothelial cells exposed to vibration. J Physiol. 2004;555(Pt 2):565-72.

7. Cracowski JL, Lorenzo S, Minson CT. Effects of local anaesthesia on subdermal needle insertion pain and subsequent tests of microvascular function in human. Eur J Pharmacol. 2007;559(2-3):150-4, http://dx.doi.org/10.1016/j.ejp har.2006.11.069.
8. Lorenzo S, Minson CT. Human cutaneous reactive hyperaemia: Role of BKCa channels and sensory nerves. J Physiol. 2007;585(Pt 1):295-303.

9. Yvonne-Tee GB, Rasool AHG, Halim AS, Wong AR, Rahman ARA. Method optimization on the use of post occlusive hyperemia model to assess microvascular function. Clin Hemorheol Microcirc. 2008;38(2):119-33.

10. Wong BJ, Wilkins BW, Holowatz LA, Minson CT. Nitric oxide synthase inhibition does not alter the reactive hyperemic response in the cutaneous circulation. J Appl Phys. 2003;95(2):504-10, http://dx.doi.org/10.1152/jappl physiol.00254.2003.

11. Zhao JL, Pergola PE, Roman LJ, Kellogg DL Jr. Bioactive nitric oxide concentration does not increase during reactive hyperemia in human skin. J Appl Phys. 2004;96(2):628-32, http://dx.doi.org/10.1152/japplphysiol.00639.2003.

12. Lenasi $\mathrm{H}$. Assessment of human skin microcirculation and its endothelial function using laser doppler flowmetry. In: Erondu OF, editor. Medical imaging. Rijeka: InTech. 2011. p. 271-96, http://dx.doi.org/10.5772/1231.

13. Flavahan NA. A vascular mechanistic approach to understanding Raynaud phenomenon. Nat Rev Rheumatol. 2015;11(3):146-58, http://dx.doi.org:10.1038/nrr heum.2014.195.

14. Suzuki J, Maeda J, Takemiya T. Analysis of microvascular responses in the finger to changes in arm position during cold water stimulation. Jpn J Physiol. 1994;44(2):181-91, http://dx.doi.org/10.2170/jjphysiol.44.181.

15. Goodfield M, Hume A, Rowell N. Reactive hyperemic responses in systemic sclerosis patients and healthy controls. J Invest Dermatol. 1989;93(3):368-71, http://dx.doi. org/10.1111/1523-1747.ep12280272.

16. Norman M, Gu L, Herin P, Fagrell B. Reactive hyperemia in term neonates and adults - A laser Doppler fluxmetry study of skin microcirculation. Microvasc Res. 1991;41(2):229-38, http://dx.doi.org/10.1016/0026-2862(91)90024-6.

17. Gemne G, Pyykkö I, Taylor W, Pelmear PL. The Stockholm Workshop scale for the classification of cold-induced 
Raynaud's phenomenon in the hand-arm vibration syndrome (revision of the Taylor-Pelmear scale). Scand J Work Environ Health. 1987;13(4):275-8, http://dx.doi.org/10.5271/ sjweh.2038.

18. Goodfield MJ, Hume A, Rowell NR. The effect of simple warming procedures on finger blood flow in systemic sclerosis. Br J Dermatol. 1988;118(5):661-8, http://dx.doi. org/10.1111/j.1365-2133.1988.tb02567.x.

19. Droste H, Wollersheim H, Reyenga J, Thien T. Vascular and humoral sympathetic nervous system reactivity during mental arithmetic in primary Raynaud's phenomenon. Int Angiol. 1990;9(2):84-9.

20. Khan F, Coffman JD. Enhanced cholinergic cutaneous vasodilation in Raynaud's phenomenon. Circulation. 1994;89(3):1183-8, http://dx.doi.org/10.1161/01.CIR. 89.3.1183.

21. Lenasi H, Strucl M. Effect of regular physical training on cutaneous microvascular reactivity. Med Sci Sports Exerc. 2004;36(4):606-12, http://dx.doi.org/10.1249/01. MSS.0000121948.86377.51.

22. Wollersheim H, Reyenga J, Thien T. Postocclusive reactive hyperemia of fingertips, monitored by laser Doppler velocimetry in the diagnosis of Raynaud's phenomenon. Microvasc Res. 1989;38(3):286-95, http://dx.doi.org/10.1016/ 0026-2862(89)90006-X.

23. Wigley FM, Wise RA, Mikdashi J, Schaefer S, Spence RJ. The post-occlusive hyperemic response in patients with systemic sclerosis. Arthritis Rheum. 1990;11(11):1620-5, http://dx.doi.org/10.1002/art.1780331103.

24. Csiki Z, Gal I, Szucs G, Andras C, Szegedi G. [Comments on Raynaud syndrome based on laser-Doppler studies]. Orv Hetil. 1999;140(41):2285-8. Hungarian.

25. Cracowski JL, Kom GD, Salvat-Melis M, Renversez JC, McCord G, Boignard A, et al. Postocclusive reactive hyperemia inversely correlates with urinary $15-\mathrm{F}_{2 \mathrm{t}}$-isoprostane levels in systemic sclerosis. Free Radic Biol Med. 2006;40(10):1732-7, http://dx.doi.org/10.1016/j.freeradbiomed.2006.01.014.

26. Gaillard-Bigot F, Roustit M, Blaise S, Gabin M, Cracowski C, Seinturier C, et al. Abnormal amplitude and kinetics of digital postocclusive reactive hyperemia in systemic sclerosis. Microvasc Res. 2014;94:90-5, http://dx.doi.org/10.1016/ j.mvr.2014.05.007.

27. Roustit M, Cracowski JL. Assessment of endothelial and neurovascular function in human skin microcirculation. Trends Pharmacol Sci. 2013;34(7):373-84, http://dx.doi. org/10.1016/j.tips.2013.05.007.

28. Cracowski JL, Gaillard-Bigot F, Cracowski C, Sors C, Roustit M, Millet C. Involvement of cytochrome epoxygenase metabolites in cutaneous postocclusive hyperemia in humans. J Appl Physiol. 2013;114(2):245-51, http://dx.doi. org/10.1152/japplphysiol.01085.2012.

29. Roustit M, Blaise S, Millet C, Cracowski JL. Reproducibility and methodological issues of skin post-occlusive and thermal hyperemia assessed by single-point laser Doppler flowmetry. Microvasc Res. 2010;79(2):102-8, http://dx.doi. org/10.1016/j.mvr.2010.01.001.

30. Tew GA, Klonizakis M, Crank H, Briers JD, Hodges GJ. Comparison of laser speckle contrast imaging with laser Doppler for assessing microvascular function. Microvasc Res. 2011;82(3):326-32, http://dx.doi.org/10.1016/ j.mvr.2011.07.007.

31. Cracowski JL, Minso CT, Salvat-Melis M, Halliwill JR. Methodological issues in the assessment of skin microvascular endothelial function in humans. Trends Pharmacol Sci. 2006;27(9):503-8, http://dx.doi.org/10.1016/j.tips.2006.07.008.

32. Saumet JL, Kellogg DL Jr, Taylor WF, Johnson JM. Cutaneous laser-Doppler flowmetry: Influence of underlying muscle blood flow. J Appl Physiol. 1988;65(1):478-81.

This work is available in Open Access model and licensed under a Creative Commons Attribution-NonCommercial 3.0 Poland License - http://creativecommons.org/ licenses/by-nc/3.0/pl/deed.en. 